\title{
La mirada del flâneur. Influjo y presencia en la poesía y narrativa de Louis Aragon
}

\section{The gaze of the Flâneur. The influence and presence in poetry and narrative of Louis Aragon}

\author{
JORDI LUENGO LÓPEZ \\ Universidad Pablo de Olavide, de Sevilla \\ jluengol@upo.es
}

\begin{abstract}
In the work of Louis Aragon, flânerie is not only present in the strolls the French writer took around Paris for pleasure, but also implies a way of locating oneself in the city and in his literature. Approaching the study of the flâneur from Aragon's poetic and literary oeuvre allows us to wander through the lines of his verses and passages of oneiric prose as though through streets and avenues, to take part in this artistic activity that irrefutably contributed to establishing him as a writer. In the present study, flanerie is therefore shown to be present not only in his Surrealist period, especially in Le paysan de Paris, but that it was a constant factor throughout all his literary work. To demonstrate this, several poems and narrative works by the French author will be analysed in depth, seeking to pin down the presence and influence of the creative gaze of the flâneur on the written text.
\end{abstract}

\section{Keywords}

Louis Aragon, Flâneur, Paris, Surrealism, Flânerie.

\section{Résumé}

Chez Louis Aragon, la flânerie se manifeste non seulement par les promenades que l'écrivain français fait pour le plaisir à Paris, mais aussi par une façon de se situer dans la ville et dans sa propre littérature. Aborder l'étude du flâneur depuis la production poéticolittéraire d'Aragon nous permet de déambuler dans les lignes de ses vers et les fragments de sa prose onirique, comme s'il s'agissait de rues et d'avenues, pour participer à cette activité artistique qui a contribué à sa consécration en tant qu'écrivain. Dans la présente étude, nous pourrons constater que la flânerie n'est pas seulement apparue dans la période surréaliste d'Aragon, notamment dans Le Paysan de Paris, mais qu'elle a été une constante tout au long de sa production littéraire. Pour cela, nous explorerons plusieurs œuvres poétiques et narratives de l'auteur français, en cherchant, dans cet exercice analytique, la présence et l'influence de ce regard créatif du flâneur sur le texte écrit.

Mots-clés

Louis Aragon, Flâneur, Paris, Surréalisme, Flânerie. 


\section{Introducción}

A aquel enigmático paseante que deambulaba callejeando por la ciudad, que con atenta mirada reparaba en aquellos inverosímiles detalles que le brindaban los sucesivos escenarios por los que transitaba, la literatura supo dotarle de un sentir poético que lo emplazaba en una entelequia urbana difícil de dilucidar. La presencia de este individuo fue advertida por primera vez por Charles Baudelaire (1821-1867), tal vez porque en su existencia se reconocía a él mismo, bautizándolo con el sobrenombre de flâneur.

Esta acepción difícilmente posee un equivalente en español, dado que se la traduce como aquel que vaga o callejea sin razón alguna, empero, en verdad, sí que la tiene. Aunque el término no se haya popularizado, coincidiendo con la producción surrealista de Louis Aragon (1897-1982), en la Residencia de Estudiantes de Madrid, José Bello Lasierra (19042008), más conocido con el sobrenombre de Pepín Bello, rememorando algún poema olvidado de Rafael Alberti (1902-1999), inventó la traducción de la palabra que mejor creía que se acoplaba a su equivalente francés: ruísta. Sin embargo, aunque la equivalencia francesa de calle era rue, y pudiera pensarse en una lógica asociación de ideas a la hora de recurrir a este adjetivo, el vocablo en sí era de lo más español, dado que los madrileños castizos, en un lenguaje coloquial, cuando salían a la calle solían decir “¡Me voy a la rué, pichi!” (Martín, 2008: 298). En realidad, el término ruismo fue inventado por Bello para justificar de algún modo sus reiteradas ausencias a las clases, una forma intelectual de hacer novillos con la que el residente convertía sus paseos por la calle en una manera productiva de hacer arte. Y, en cierto modo, así lo hacía, porque tras sus caminatas sin rumbo, siempre era reclamado por sus compañeros de Residencia, hasta tal punto que, como apuntaba el polifacético escritor José Bergamín (1895-1983), muchas de las grandes ideas que tuvieron Federico García Lorca (1898-1936), Luis Buñuel (1900-1983) y Salvador Dalí (1904-1989) provenían de la actividad ruísta de Bello (Sánchez, 1996: 49-52). Un flâneur español que, si bien hubo antes otros, siendo con toda probabilidad conocedor del término y de su procedencia baudeleriana, entre risas y bromas, y sin tener repercusión alguna, acuñó un vocablo con el que todavía hoy se le asocia.

En lo atinente al surrealismo, se sabe que muchas de las ideas que aparecieron en el film Un chien andalou (1929) de Buñuel, como el "carnuzo" o burro en descomposición o la mano con hormigas, fueron imaginadas por Bello durante uno de sus paseos a raíz de alguna de las muchas escenas callejeras que contemplaba. El cineasta aragonés llegó incluso a escribir, en colaboración con Bello, en 1927, en el café Le Select de París, una parodia trágico-cómica de Hamlet, la cual es hoy considerada como la primera pieza surrealista del teatro español (Havard, 2004: 187). La participación de Pepín Bello en esta obra fue por correspondencia, y se desconoce qué es lo que en concreto aportó al escrito, pero no cabe duda de que las ideas que en él se plasmaban eran consecuencia de su creativo vagar urbano. 
El ruismo se caracteriza por un deseo incontrolable de querer conocer todos los sentimientos que suscita la atmósfera urbana sobre los individuos y, al mismo tiempo, indagar en sus características e implicación con la ciudad. El flâneur sale a la calle, como cualquier artista cuando inicia su obra o estudioso aborda un texto para su análisis, disponiéndose a crear y a aprender de todo aquello que lo rodea. Tras volver de su incursión, este vuelca todos los conocimientos "aprehendidos" en este particular ejercicio sobre aquello en lo que con rigor trabaja para conseguir el resultado anhelado. Walter Bejamin (1892-1940), al referirse a Baudelaire, describía este proceder con la acepción francesa "herboriser sur le bitume" (herborizar sobre el asfalto), puesto que el escritor alemán, al igual que el poeta francés, también se consideraba un flâneur que buscaba su inspiración en los rostros, actitudes y procederes de los transeúntes que se cruzaba en la acera (Benjamin, 1982: 57; apud: Dahlem, 2009: 188). Sus pasos nunca respondían a un plan racional, ni su observación se limitaba a un otear frío y objetivo de lo que le rodeaba, sino únicamente al placer de transitar por las calles de la ciudad, descubriendo nuevos recovecos, sendas y gentes con las que poder estimular su imaginación. En palabras del polifacético autor argentino Roberto Arlt (1900-1942), se trataba de convertir en oro el barro de la calle, buscar todo lo extraordinario que en ella se percibía, las cosas que se veían, las palabras que se escuchaban o las tragedias que se llegaban a conocer. Un ejercicio que sólo un flâneur podía llevar a buen término, porque se debía estar predispuesto a ello y salir con el firme convencimiento de que esa era su función: la de disfrutar viviendo de la calle y sus gentes para hacer de esa acuarela de existencia urbana un referente de imaginario social del que poder nutrir el alma:

Para un ciego, de esos ciegos que tienen las orejas y los ojos bien abiertos inútilmente, nada hay para ver en Buenos Aires, pero, en cambio, iqué grandes, qué llenas de novedades están las calles de la ciudad para un soñador irónico y un poco despierto! ¡Cuántos dramas escondidos en las siniestras casas de departamentos! ¡Cuántas historias crueles en los semblantes de ciertas mujeres que pasan! ¡cuánta canallada en otras caras! Porque hay semblantes que son como el mapa del infierno humano. (Arlt, 1995 ${ }^{1933}:$ 92-93)

Arlt describe al flâneur como un soñador cargado de ironía y lo suficientemente despierto como para advertir todos los sucesos que acaecían en su deambular callejero, así como la variopinta variedad de personas que los protagonizaban. La seriedad en el ruismo no tiene razón de ser porque en él se busca metamorfosear el significado de todo aquello que se percibe e inventar una nueva identidad de los sujetos que intervienen en ese proceso de asimilación y transformación de lo captado. Un fenómeno que encajaba también con el sentir y la reinterpretación de la realidad desde los presupuestos surrealistas, en tanto que la percepción de los estímulos que se recibían del exterior terminaban de perfilarse en la imaginación creativa del artista o literato. 
Louis Aragon sabía de la importancia de la flânerie a la que también otorgaba ese tono burlón al concebirla como un juego, pues los surrealistas recurrían a la interpretación lúdica de lo que les rodeaba para atrapar la mente consciente y alimentarse directamente de la imaginación deseada (Bradley, 1999: 24). Esta concepción de la flanêrie como elemento lúdico de un telúrico deambular, el escritor francés seguirá aplicándola incluso después de su ruptura con el surrealismo en 1932 (Kopp, 2008: 185). Esta metamorfosis conceptual de la calle a través de la flânerie podrá constatarse en su poemario Le Fou d'Elsa', escrito en 1963, en plena madurez del autor, donde contaba cómo los niños ${ }^{2}$ trasformaban las aceras con sus dibujos y trazos con tiza, esbozando rayuelas de colores u otros juegos que les sugiriera su imaginación: "Ainsi les enfants font de la rue un jeu tatoué les nomades un langage entre eux que ne comprend point la maison marquée ou des hommes aux yeux fuyants le blasphème et l'obscénité" (Aragon, 1963: 56). El flâneur juega con la calle con el propósito de cambiarla en función de todo aquello que ve en sueño. Un mundo onírico que, a su vez, se encuentra influenciado por lo aprehendido en sus paseos ruistas y que el escritor intenta reinterpretar a partir de su propia identidad como individuo. Aragon se deja llevar por el espacio urbano al transitar por él sin rumbo definido, fluyendo a la merced del azar, como todo artista-creador o incluso como aquel flâneur descrito por Walter Benjamin, que, aún algo burgués, deambula a la deriva por los pasajes parisinos con el objeto de escapar al sórdido mundo de lo racional (Trudel, 2009: 5; Turcot, 2014: 51). La libertad del juego, pese a sus reglas, fácilmente maleables por la mente e imaginación de un niño, permite al flâneur aventurarse a una sana interpretación de la realidad que le permite acompasar su actividad ruísta con su capacidad creativa.

\section{2. Ô mon amour ô ma blessure: la cara oscura de la flânerie}

Con todo, el flâneur no siempre puede aplicar su magia conceptual para cambiar la realidad en algo onírico, en una idealidad mucho más hermosa e interesante a ojos del artista, porque no siempre es posible cristalizar ese deseo. Esta actividad transformativa se trunca cuando el horror penetra en la mirada del flâneur, bloqueando su capacidad

1 Luis Aragon estuvo "embrujado" por su mujer, Elsa Triolet (1896-1970), desde el mismo instante en que la conoció, lo que le llevará a escribir varios poemas recurriendo frecuentemente a su nombre para darles título. Uno de estos fue Le Fou d'Elsa, escrito en 1963 por un ya maduro Aragon, quien decidía contar la caída de Granada, en 1492, a manos de los cristianos. Aragon manifiesta un claro sentimiento de empatía onírica hacia Boabdil, el último rey de esta ciudad andaluza, a quien defenderá recurriendo a la fuerza del tiempo y de los sueños que del sortilegio de su reino se desprendían: “ces rêves qu'on retrouve, ces rêves rerêvés qui vous ramènent à une maison qu'on n'a jamais vue, un monde uniquement nocturne, avec les liens entre ceux qui nous entourent éveillés, tout y est changé, les sentiments, les hiérarchies, la philosophie ou la religion, les codes, les coutumes, les vêtements" (Aragon, 1963: 11). Dichos sueños, no obstante, estarán influenciados por la realidad que en aquel momento vivía el autor, la cual no era otra que la de la Guerra de Argelia (1954-1962), donde cristalizaba otro objetivo de resistencia, aunque en esta ocasión ante el imperialismo francés.

2 Sírvase en adelante la utilización del genérico masculino para referirse tanto a mujeres como a hombres. 
creativa y, anulando cualquier interpretación lúdica que entre risas y sorpresa pudiera plasmarse en su proceso de captación y posterior exteriorización artística. Existen, por lo tanto, elementos e individuos que usurpan el espacio de este paseante urbano, convirtiendo el sueño en pesadilla. Cuando eso ocurre, el subconsciente pierde entonces su poder para introducir el miedo en la mente del escritor, trastocando este su quehacer entrópico en un razonamiento consciente de orden impuesto, donde todo aquello que escapa de él no sólo está fuera de lugar, sino que además está proscrito y castigado. Así, cuando las tropas alemanas entraron en París, en aquel 14 de junio 1940, el flâneur toma conciencia de que existe otro flâneur, un flâneur oscuro que deambula por las calles de París sin dejarse llevar por el azar, que no observa las particularidades de todo aquello que asalta su curiosa mirada de niño, sino que marcha al unísono con otras réplicas uniformadas de sí mismo y bajo el emblema de un único símbolo (Boireau, 2013: 223). Los nazis ignoraban la belleza de la naturaleza urbana, y la morfológica diversidad del rostro de las gentes que la poblaban, aunque sí que metamorfosearon las calles con su "voluntad creadora", la cual no tenía más objeto que la de imponer su forma de ver el mundo. Esta dual tipología de flânerie podemos constatarla en Le Crève-cœur de Louis Araron, un compendio de poemas ${ }^{3}$ escritos entre octubre de 1939 y octubre de 1940 , donde el autor manifiesta su desazón ante el descubrimiento de ese flâneur que invadía el espacio que, en París, al artista y escritor surrealista le era propio:

\author{
Semblables à des ombres peintes \\ Un passant qui soudain les vit \\ Sauvagement rit de leurs plaintes \\ Un passant qui soudain les vit \\ Il était noir comme les mines \\ Il était noir comme la vie \\ Il était noir comme les mines \\ Ce géant qui rentrait chez lui \\ A Méricourt ou Sallaumines [...] \\ Les géants qui se profilèrent \\ Sans même un bâton dans la main \\ Les géants qui se profilèrent \\ Sur le ciel blanc de la colère. (Aragon, 1946: 48-49)
}

3 Le Crève-cœur es una obra que debe ser concebida como una reivindicación al derecho a ser libre, pero una libertad entendida como se laisser-aller, dejarse llevar por los sucesos que acontezcan a su alrededor para poder crear al son de ese sentimiento reivindicador: "Univers inconnaissable par les moyens rituels de la science, nous l'atteignons par le travers des mots, par cette méthode de connaissance qui s'appelle la poésie, et nous gagnons ainsi des années et des années sur le temps ennemi des hommes" (Aragon, 1946: 67). La rima retoma entonces su dignidad perdida, porque es ella quien debe introducir la novedad en el viejo y clásico lenguaje, ya que, según Aragon, ese es precisamente su fin y a ese proceso es al que llamamos poesía. 
Este azaroso entrecruzamiento entre flâneurs hará que el oscuro color de esos soldados se traslade al corazón de Aragon, quien, captando el sentir de la población, permeabilizará la angustia de sus retinas en el fondo de sus almas. El flâneur artista ya no podrá tomar prestados aquellos colores que apercibía en su ruísta labor de aprehensión poética, ni siquiera podrá nutrirse de la idílica variedad de grises con la que tantas veces se tiñe París durante los días de otoño e invierno, sino que un negro profundo, un acromatismo de tristeza y desolación, cubrirá las calles de la capital francesa y, con ellas, su voluntad creadora.

En las páginas de Le Crève-cœur encontramos a un Aragon que maneja el lenguaje a placer, esgrimiendo cada palabra al compás de los anhelos marcados por su espíritu y sensibilidad, pues, viendo la trágica situación en la que se hallaba Francia, y muy particularmente París, ciudad en la que desarrollaba su actividad ruísta, decidió hacer de su poesía un himno de resistencia y libertad (Grenouillet, 2010: 240; Jauer, 2007: 94). En aquellos momentos era imperativo cantar a todo aquello con lo que el flâneur se había cruzado y/o fijado en su deambular callejero, independientemente de su naturaleza o aparente funcionalidad, porque encumbrar la belleza de lo más insignificante era lo único que podía hacerse para sobrellevar todo ese horrible horror: "Jamais peut-être faire chanter les choses n'a été plus urgente et noble mission à l'homme, qu'à cette heure où il est profondément humilié, plus entièrement dégradé que jamais" (Aragon, 1947: 67). Un imperativo categórico que, sin buscarlo, había caído sobre los poetas, y no sólo sobre los que tendían a diluir su espíritu en las calles de la capital francesa, sino también sobre otros tantos que desde su percepción poética eran igualmente conscientes de lo indigno de toda aquella triste situación: "Et nous sommes sans doute plusieurs à en avoir conscience, qui aurons le courage de maintenir, même dans le fracas de l'indignité, la véritable parole humaine, et son orchestre à faire pâlir les rossignols" (Aragon, 1947: 67). En aquel París ocupado, la existencia se había vuelto negra como las minas de carbón, como el ánimo de todos aquellos transeúntes que ahora se olvidaban de observar todo aquello con lo que les sorprendía el azar, porque andaban con la mirada perdida o fija en un punto concreto para no ver las macabras escenas que acontecían en las aceras de su ciudad.

Ante este sombrío escenario en el que se había convertido París, adelantándose incluso al fatídico día de la marcha de aquellos lúgubres flâneurs uniformados sobre sus calles, en la mañana del 10 de mayo de 1940, cuando la radio informaba de la entrada de las tropas alemanas en territorio francés, en una terraza de un café, Aragon manifestaba todo su dolor con el verso último de un poema interrumpido 4 por la presentida llegada de esa flânerie vestida de negro: "Ô mon amour ô ma blessure" (Charpentier, 2008: 55). Para el escritor francés, como confesaba años más tarde, en 1956, en Le roman inachevé ${ }^{5}$, ese fue uno de los puntos

4 El título en francés de este poema era el de "Le poème interrompu" (Aragon, 1956: 38-39).

5 Le roman inachevé es una obra autobiográfica que se encuentra escrita en verso en la que Aragon nos cuenta su trayecto de vida hasta ese preciso momento. Es una novela inacabada porque, en ella, faltan por contar aquellos años que todavía le quedan por vivir. En este experimento literario, el autor se niega a narrar su 
de inflexión de su existencia, ese preciso instante donde el París de su juventud pasaba a convertirse en "Paris de l'An Mille", aquel que estaba preso de los terrores milenarios y de la incertidumbre de lo que entonces vendría, cuya metamorfosis cantaba con los siguientes versos:

\author{
C'était le Paris de l'An Mille \\ Adieu ma vie adieu ma ville \\ Pont Alexandre pâle et beau \\ Le soir comme un vers de Rimbaud \\ Ma Tour au loin qui semble un air \\ Renouvelé d'Apollinaire. (Aragon, 1956: 51)
}

Aragon se despedía de todo aquello que simbolizaba París para volverse a encontrar con una ciudad imbuida de los terrores milenarios, próxima al pavor que genera el saberse cerca del fin del orden establecido, del ocaso de todo lo conocido, del apocalipsis total. Sin embargo, pese a ese sentimiento de sempiterna desolación, el escritor surrealista pide al imaginario colectivo francés que abandone ese terror para abrazar la esperanza del advenimiento de un nuevo orden, porque sólo de este modo podría avanzarse en el devenir de la nación hacia una nueva realidad. En ese universo renacido, sus habitantes volverán a ser aquellos seres alegres que fueron antes de la llegada de los flâneurs uniformados de negro y podrán transitar de nuevo por las calles de París inmersos en esa flânerie que preside el gozo y la alegría de un infante:

L'ordre est mis à jamais dans les grands ossuaires
Spectres de mon pays reposez, reposez
Laissez sur vous tomber la dalle et le suaire
Ne faites plus chez nous ce bruit du cœur brisé
Ne revendiquez plus au foyer votre place
Et ne gémissez plus le soir à la croisée
Ne venez pas troubler le pas des amoureux
Laissez l'oiseau chanter laissez l'ombre être douce
Laissez les jeunes gens s'en aller deux par deux
Que la tombe s'apaise et se couvre de mousses
Que la terre mouillée en étouffe les bruits
Voyez l'herbe se lève et le taillis repousse. (Aragon, 1956: 66)

existir como si de una retahíla de acontecimientos se tratase, los cuales tan frecuentemente son contados con indolencia y sin pasión alguna, para hacerlo con el entusiasmo y el placer que siempre le ha dado la escritura (N'Guessan, 2018 2010: 18; Walker, 2005: 30). Sin embargo, en sus líneas puede percibirse cierta melancólica languidez a la hora de relatar sus memorias, a la vez que se presiente una profunda desilusión ante todo lo acontecido hasta ese momento, pues confiesa no haber conseguido alcanzar aquello que se proponía, que, por otra parte, nunca revelará. Una reflexión que nos conduce a preguntarnos sobre el sentido último de la existencia humana. 
Un canto a la gloria del sufrimiento vivido por el pueblo francés, al que se le pedía dejar que, en su espíritu, se asentara aquel dolor latente por todo lo que se había perdido en la contienda bélica. Atenazado este sentimiento en lo más recóndito de su ser, la poesía de Aragon se convertía así en "un grito de cólera, de dolor, de esperanza, en un canto de guerra y de amor, en un arma de combate contra el invasor nazi y contra los colaboracionistas franceses" (Solà, 2014: 271). Versos en los que se imploraba que la violencia, las afrentas y las múltiples vejaciones, que sobre el suelo galo se cometieron, no se olvidaran, sino que se aprendiera pronto a vivir con ellas. Y que, con ese sabio aprendizaje, todo regresara a la “normalidad", que la belleza de la naturaleza y el amor exteriorizado por la juventud volviera a manifestarse sin condicionante alguno, y, todo ello, en un escenario ideado para la creación poética y no para la muerte y la desolación.

\section{París, mise en scène de la flânerie}

Posee el flâneur surrealista cierta afinidad con la atractiva poética de la precariedad al frecuentar aquellos lugares de ocio - y ociosidad — urbano, oriundos de los bajos fondos ocultos -aunque no desconocidos- a las mentalidades biempensantes, como las tabernas, los baños públicos, los burdeles o los cabarets de tercer orden, donde a diario se respira el aire viciado de la sensualidad meridional. La ciudad es artificial, pero al mismo tiempo muy humana, y su universo subterráneo se desarrolla de forma distinta a cómo lo hace el que es por todos conocido y, en teoría, responde a unos cánones de moral establecidos. Un orbe dual que, al igual que los grandes bulevares, plazas turísticas y avenidas concurridas por damas pudientes sedientas de la novedad de los comercios, también tuvo su impacto sobre los artistas surrealistas, pues era considerado por estos de análoga o superior belleza a la que podía contemplarse durante las horas de luz diurna (Cuvardic, 2012: 346). Aragon, en su poema "Les amants séparés", recogido en su obra Le Crève-cœur, aseguraba que en esas aceras y esquinas pegajosas por suelos machados de alcohol y orina, era posible encontrarse "lilas suburbains", cuya belleza era mucho más excelsa que cualquier expresión floral existente (Aragon, 1946: 42-46). El flâneur tendrá la misión, y la obligación, de descubrir esas flores para enmelar su obra creativa de perfume urbano y colorario celeste.

Con todo, para encontrar esa belleza, este ruista transeúnte tenía que ser todavía joven, ya que debía de poder ser capaz de introducirse en todos esos lugares que Baudelaire emplazaba dentro de la nostalgie de la boue, sin generar en sus parroquianos ninguna mirada de desconfianza, ni de aprensión de formas. Esas siringas ${ }^{6}$ nunca podrían ser retiradas de los grisáceos suelos de la sucia naturaleza urbana por un hombre ya maduro, dotado de esa mezcla de juicio y prudencia que trae consigo el paso de los años. En su poema "La valse des

6 Nombre botánico de las lilas. 
vingt ans", Aragon matizará, además, que sólo cuando uno se halla en sus años de juventud, dulce fluir de equivocación constante, tentaciones latentes y decisiones apresuradas, puede mezclarse con una inocente sonrisa entre la muchedumbre del suburbio sin despertar sospecha alguna. Un baile que llevará al flâneur a penetrar en los bistrós y romper a carcajadas en las bocas del metro (Aragon, 1946: 27), como si cayera en un estado latente de locura sin ningún tipo de cura.

París es la ciudad donde se desarrollan un considerable número de novelas surrealistas y donde la flânerie está presente a lo largo de la trama que en ellas se expone. André Breton no dejará de recorrerla en Nadja, al igual que tampoco lo hará Louis Aragon en Le Paysan de Paris, siempre desde la sempiterna dualidad entre lo real y lo onírico, en busca de esa necesaria inspiración para su arte (Cuvardic, 2012: 113-116; Huebner, 2014: 281; Hoyos, 2013: 78-80). Para ambos autores, la calle era su único campo de experimentación y a él se brindaban para descubrir lo que en su seno escondía, su auténtica forma, esa que iba más allá de lo que a primera vista se mostraba y que sólo el artista surrealista podía percibir: “ce n'est pas moi qui méditerai sur ce qu'il advient de 'la forme d'une ville', même de la vraie ville distraite et abstraite de celle que j'habite par la force d'un élément qui serait à ma pensée ce que l'air passe pour être à la vie" (Breton, 1998 ${ }^{1928: ~ 155) . ~ L o ~ o n i ́-~}$ rico, el mundo del sueño, por lo tanto, es el lugar desde el que se puede captar esa peculiar morfología urbana.

La Nadja de Breton se encuentra siempre en un estado de locura, muy próximo al trance, en el que tiene visiones y alucinaciones que le permiten predecir el futuro. En ella, el surrealismo se hallaba en su estado puro, no adquirido, por lo que aquellos artistas que carecían de ese don, entre los que paradójicamente se encontraba el propio Breton, no sólo no lograban entenderla, sino que, además, experimentaban cierta tendencia a alejarse de esta mujer, pues no podían ni siquiera compartir "las cosas simples de la existencia" (Breton, $1998^{1928}$ : 134). Con todo, y a pesar de esa particularidad, la atracción que esta mujer generaba sobre el autor era tal que muy frecuentemente se confundía con el amor, un amor entendido bajo un sentido absoluto, concebido por ambos como una revolución necesaria hacia la consecución de la libertad, hacia un sentirse libre de todo aquello oriundo del mundo real que condicionara y coaccionara su voluntad creativa.

De igual modo, Aragon, convertido en un moderno "campesino" urbano, también constatará este fenómeno de enajenación mental en su por entonces flânerie surrealista, la cual expondrá en su obra Le Paysan de Paris, escrita entre 1924 y 19257, en pleno auge del movimiento artístico-literario. A través del ruismo del escritor, este "abre los ojos" a todos aquellos jóvenes, provincianos y extranjeros, que por primera vez visitan París para

7 Inicialmente lo hizo, en 1925, en la Revue Européenne, pero un año más tarde la publicó en la editorial Gallimard, cuya edición es la más conocida (Walz, 2000: 161). Con esta obra, Aragon pretende abrir conciencias a todos aquellos individuos foráneos que llegan a la ciudad de París, con el objeto de que contemplen aquello que les rodea desde la mirada del flâneur surrealista. 
mostrarles lo profundo de su alma y su fisonomía oculta. Una pequeña guía con la que cualquiera puede deambular por las calles de la ciudad compartiendo la flânerie de su autor, apartándose así del universo conocido como real para esbozar una nueva panorámica delineada con los trazos nacidos del subconsciente y el sueño (Chamarat-Malandain \& Leroy, 2007: 248; Narjoux, 2002: 80). Aragon erra por el Pasaje de la Ópera ${ }^{8}$, cuyas obras amenazaban la permanencia del aspecto original del bulevar Haussmann, aplicando en su ruismo una mirada diferente con la que capta todos aquellos espectáculos que se anuncian con pancartas y se exponen en vitrinas. Con pasos errantes, el escritor pasea por la calle Chauchat aux Buttes-Chaumont, donde se detiene por unos instantes para percibir mejor todo aquello que emana del entorno urbano con el fin de bosquejar un posible futuro intelectual que se erija desde la más férrea condena al idealismo. Poco a poco irá colmándose de toda una serie de auténticos documentos visuales aprehendidos gracias a breves momentos de reflexión ante los teatros, los grandes almacenes, los baños públicos, los prostíbulos y los comercios, ante todo aquello que puede encontrarse en forma de átomos errantes en el espacio urbano. En este ejercicio queda de manifiesto que la flânerie es parte integrante del propio surrealismo, un elemento constitutivo del movimiento artístico que, más que como una corriente estética establecida, se muestra como un "vicio" en sí, cuya adicción es necesaria para poder crear:

Le vice appelé Surréalisme est l'emploi déréglé et passionnel [sic] du stupéfiant image, ou plutôt de la provocation sans contrôle de l'image pour elle-même et pour ce qu'elle entraine dans le domaine de la représentation de perturbations imprévisibles et de métamorphoses: car chaque image à chaque coup vous force à réviser tout l'Univers. (Aragon, 1926: 83)

En ese mismo Pasaje de la Ópera de París, en el que fuera también cenáculo de los dadaístas con Tristan Tzara (1896-1963), Aragon y otros surrealistas, como fueron André Breton, Marcel Duchamp (1887-1968), Max Ernst (1891-1976), Jean Arp (1886-1966), René Crevel (1900-1935) o el propio Tzara, dieron con un punto de encuentro desde el que poder mostrarse los unos a los otros los lienzos imaginarios que habían pintado con los colores vistos en sus parisinas marchas ruístas (Brooker, 2013: 35). Un enclave emplazado en la gran ciudad donde las imágenes grabadas en las retinas de todos ellos se agolpaban en una onírica confluencia de Utopos y Ucronos — fuera del espacio y del tiempo - para delinear el modus operandi de un movimiento artístico que en aquel entonces empezaba a consolidarse.

Una de las particularidades que potencia y hace rica la actividad de la flânerie es el hecho de que, en las ciudades, los lugares por los que se transita no siempre son los mismos, ya que estos desaparecen al transformarse las aceras de las calles por las que se ha

8 Curiosamente, Nadja también tendrá por costumbre pasear por este Pasaje (Breton, 1998 ${ }^{1928}:$ 39). 
circulado en sendas jamás vistas pobladas de huellas desconocidas, que rodean edificios en continuo cambio y evolución. Un pasaje onírico perdido en la inmensidad del olvido en el que el flâneur surrealista debe emplazarse. Aunque ya lejos del surrealismo, esta evidencia puede constatarse en la producción literaria de Louis Aragon dentro de la novela Blanche ou l'oubli', escrita en 1967, donde su protagonista, Geoffroy Gaiffier, un lingüista jubilado, manifiesta este fenómeno de pérdida de la realidad conocida a medida que llevaba a cabo su ruísta deambular:

Je regarde ma rue et je ne sais plus dans quelle ville je suis, je regarde ma main comme une étrangère, dans une chambre d'où personne ne songe à me chasser je dévêts un corps inconnu, un corps d'homme vieilli, marqué, de toutes parts alourdi qui obéit à ma pensée, et je me tais pour voir s'il va parler à ma place. (Aragon, 1967: 134)

El proceso de desaparición de la calle durante la flânerie no atañe únicamente al espacio físico por el que vaga este individuo, sino que afecta al propio cuerpo del flâneur. Una metamorfosis que lleva a que el artista que busca su inspiración en la calle sea consciente de que los cambios acaecidos en su ciudad también se operan en su rostro y en todo su cuerpo (Kaufmann, 2014: 58). Las ciudades se transforman, envejecen y se renuevan, al igual que ocurre con el flâneur, pero mientras que una ciudad sigue manteniendo su identidad, este personaje ve cómo el tiempo se le ha pasado, sus pasos ya no responden al trote exigido para llevar a cabo esta actividad y es preciso que otros tomen su relevo, pero no como obligación, sino por el placer de ejercer este "oficio", cuya base es el gozo de la "creatividad sobre la marcha".

\section{La temporalidad de la flânerie}

La temporalidad del flâneur es constante y $\sin$ fin. Una actividad que se da tanto de día como de noche ${ }^{10}$, pues la luz que la ciudad recibe del Sol ${ }^{11}$, en sus horas de ausencia, se encuentra tamizada por una infinidad de intensos puntos de luminosidad que sólo son perceptibles por la mirada de este avezado paseante. Una monstruosa tela negra que se expande sobre el cielo tatuando con su sombra nuevas geometrías sobre la ciudad con una amplia amalgama de grises oscuros, pero con azarosos destellos fluorescentes. Con ello, esta particu-

9 Blanche et l'oubli es una novela donde el lenguaje se encuentra organizado por sí mismo, como ocurre en otras obras ya mencionadas de Aragon, siendo, a su vez, una relectura más de la propia vida del escritor surrealista (Piégay-Gros, 2014: 37).

10 Esta temporalidad de la flânerie sin límite establecido, perenne en el día y la noche, se advertía ya en los versos del poema "Zone", recogido dentro del poemario Alcools, publicado en 1913, donde Guillaume Apollinaire (1880-1918) describía su actividad ruista desde primeras horas de la mañana hasta el amanecer del día siguiente.

11 Para Aragon, el astro solar se encuentra siempre bajo nuestro control, por lo que no sólo sigue nuestros pasos en la actividad ruista, sino que además obedece a nuestra caprichosa voluntad: "le soleil est mon petit chien. Il me suit comme tu peux voir" (Aragon, 1926: 54). 
lar luz nocturna abría un amplio abanico de posibilidades interpretativas al artista surrealista, que el flâneur aprovechaba para aunarla con su actividad onírica y dar forma así a ese sentir furtivo aprehendido en sus paseos noctívagos:

La nuit de nos villes ne ressemble plus à cette clameur des chiens des ténèbres latines, ni à la chauve-souris du Moyen Âge, ni à cette image des douleurs qui est la nuit de la Renaissance. C'est un monstre, immense de tôle, percé mille fois de couteaux. Le sang de la nuit moderne est une lumière chantante. Des tatouages, elle porte des tatouages mobiles sur son sein, la nuit. (Aragon, 1926: 175-176)

Una luz que resulta ser temible y encantadora a la vez, la misma que se percibe en los pasajes nocturnos teñidos de puro erotismo, el cual se tatúa en el espíritu del artista surrealista condicionando su actividad noctívaga y su producción poética. Así, en Le Paysan de Paris, la razón denuncia a Aragon la "dictadura de la sensualidad" en la que se encuentra anclado, puesto que él mismo declara sentirse irremediablemente atraído por toda aquella atmósfera de lascivia color carmesí (Narjoux 2002: 56; Forest, 2008: 89). El escritor parisino se verá cautivo de la seducción de los baños públicos, de las casas de lenocinio y de las camufladas prácticas que, en la oscuridad, meretrices de baja estofa llevaban a cabo en el Théâtre Moderne. He ahí por lo que a Louis Aragon se le acusará de ensalzar la prostitución, y con razón, dado que su idea comunista del amor libre no sólo direccionaba sus pasos hacia esa moderna nostalgie de la boue baudeleriana, sino que, además, se extrapolaba a distintas dimensiones del orden social con el que nunca cesará de pensar y comprometerse (Aliaga, 2007: 131; Dupouy, 2006: 75; Lemonnier, 2008: 204). Esto justifica que el escritor parisino considerara que a la maison de tolérance se le debía conceder el reconocimiento de ser, en el furtivo vagar ruísta, un enclave de libertad creativa.

Para Aragon, el principio del amor se halla al margen de la ley, cuya cristalización se da en un sentido irreprensible del delito, un claro desprecio a la prohibición y un eminente gusto por el expolio (Aragon, 1926: 66). La base del amor surrealista, tal y como lo entendía en Le Paysan de Paris, por lo tanto, reside en la identidad femenina, en una identidad resignificada a partir de las pautas conductuales y de pensamiento desarrolladas por las mujeres que son libres. De este modo, el amor se convierte en una religión que se profesa incondicionalmente, cuyo templo se encuentra en los suburbios de la ciudad, siendo las prostitutas sus sacerdotisas, y en cuyo culto, además, no hay confusión moral alguna, ni dilema en el que perderse al querer dilucidar sobre qué es el bien y el mal. Una disyuntiva ética que deviene irrelevante al constatarse que dicho lugar es un mero ensayo de naturaleza muerta (Aragon, 1926: 61), un capricho entre las geometrías de la metrópoli, donde el artista puede detener su flânerie para integrarse en el medio.

Al igual que la noche, la calle lleva consigo la ambivalencia que puede percibirse en el erotismo, dado que su seno se caracteriza por ser agradable y peligroso, reconfor- 
tante y temido a la vez, un espacio donde es posible crear la atmósfera adecuada para la creatividad. El noctívago flâneur se funde en el universo urbano que envuelve esos paseos a altas horas de la noche, vagando por las calles oscuras o apenas iluminadas, buscando encontrar, en medio de la penumbra, un indicio que sirva para descubrir el sentido de su próxima obra escrita (Montiel, 2005: 14; Nesci, 2007: 77). Con ese proceder, y desde el silencio de la reflexión creativa, su mirada traspasa el negro manto del cielo nocturno para proponer una realidad afín a la de sus sueños. Se hunde voluntariamente en un mundo que va descubriendo poco a poco gracias a su voluntad artística, sin haber resistencia alguna en ese viaje de perpetuo hallazgo, ni tampoco barrera que le impida seguir avanzando libremente sobre la acera, mirando todo aquello con lo que se cruza, sin miedo al fulgor de lo auténtico, ni de la vida misma que, en última instancia, supone ser la única verdad del universo.

Esta ruptura de las reglas establecidas por amor en la noctívaga actividad urbana, al igual que ocurre con la diurna, se advertirá también en el sentimiento que Aragon profesa a Elsa Triolet. Así, en el poemario Le Fou d'Elsa, Aragon aparecerá como un flâneur enajenado que ya no se pasea por las calles de la gran ciudad, sino a través del tiempo con la fuerza de sus sueños y la pasión que siente por su mujer:

\author{
Quel être suis-je et d'où l'image \\ Quel homme suis-je ou son reflet quel est moi celui qui regarde et se tient \\ au parvis des temps ou l'autre outre-miroir qui rêve \\ Suis-je celui qui se retourne et se cherche dans le passé suis-je celui qui \\ marche à l'avenir le devançant dans sa folie \\ Suis-je dans ce qui fut ou dans ce qui sera \\ Suis-je qui l'invente ou le Fou. (Aragon, 1963: 394)
}

Con todo, esta flânerie no sólo será una senda por la que poder transitar sobre la curva del tiempo, sino también un medio para poder contemplar el futuro. Louis Aragon incidirá en esta última particularidad al recordar el poder adivinatorio que poseía Ibn-Amir a quien consideraba otro flâneur que tenía el don de deambular por su propio interior, como si su espíritu fuera una calle poblada de desconocidos recovecos, observando la mirada de las gentes que por ella transitaban: "Lui C'était dans la rue entouré par les autres/Il a regardé l'avenir puis il a regardé les gens" (Aragon, 1963: 290). El ruismo implica observar a los otros mientras se circula por la acera, contemplar sus rostros, incidir en sus expresiones, pero sobre todo conlleva analizar la forma que estos tienen de concebir el espacio urbano, el propio universo, que, en este caso, se permeabilizaba en el poder adivinatorio y la capacidad de viajar en el tiempo. Existirá, por lo tanto, cierta reciprocidad entre las calles y quienes por ellas trancurren, mezclándose sus espíritus con la configuración misma de la ciudad, cuyas aceras se asfaltan con los sueños del flâneur, que, sin espacio, ni tiempo, se ve preso de esa irresistible necesidad de andar para crear. 


\section{Cuando la locura humana deambula por las aceras de la ciudad}

En el deambular callejero del flâneur son muchas las psicologías que asaltan su observación analítica del espacio urbano y sus componentes. Estas singularidades de pensamiento se entrevén en las miradas furtivas de sus transeúntes, donde, además, es posible advertir el carácter moral que las esculpe. Aquellos escritores que se daban con agrado al ruismo encontraron un poderoso objeto de interpretación del que poder escribir y así exteriorizar las extravagancias de su pensamiento, que, con sutileza y poca honestidad, atribuían a los personajes ficticios con los que se habían cruzado durante su flânerie (McCabe, 2014: 303; Nesci, 2007: 259). Pronto, esos amenos relatos inventados para el deleite de un público lector poco exigente, que se leían en horas muertas por deleite, pasaron a convertirse en documentos de estudio y análisis de una nueva ciencia denominada Psicoanálisis.

Los surrealistas profundizarán en el funcionamiento psíquico de su actividad poético-creativa y la consecuente cristalización de sus sueños a través del arte. En el Manifeste du Surréalisme, escrito por André Breton, en 1924, encontramos un elogio a la locura, donde se indica que ese estado de enajenación mental posee el supremo valor de la imaginación: "Les confidences des fous, je passerais ma vie à les évoquer. Ce sont gens d'une honnêteté scrupuleuse, et dont l'innocence n'a d'égale que la mienne" (Breton, 1966"1924: 213; apud: Bénézet, 1996: 213). Al igual que los futuristas, y muy en particular que el escritor italiano Filippo Tommaso Marinetti (1876-1944), Breton creía que los locos, junto a los niños, terminarían por heredar el mundo. Para el poeta y escritor surrealista, todo individuo que estuviera loco era víctima de su propia imaginación, siendo esta la principal causa de su reclusión en una clínica psiquiátrica o asilo de locos (Caballero, 2002: 122; Scopelliti, 2002: 22). El hecho de apartarse de la "normalidad" conducía a la sospecha de las mentalidades biempensantes, que no entendían los comportamientos extraños de estos individuos y terminaban por condenarlos, cuando, en realidad, la única diferencia con los surrealistas era que su fânerie la llevaban a cabo en aquellos lugares más remotos de su pensamiento, los cuales, al detectarlos, se exteriorizaban en su cuerpo como estigmas de un arte velado.

Nadja es un claro ejemplo de este fenómeno. Sin embargo, pese a la originalidad de sus dibujos y, su manifiesta atracción por la flânerie y el sortilegio que sobre su espíritu esta actividad provocaba, la heroína de la obra de André Breton terminará recluida en un manicomio. Esta determinación por parte del escritor surrealista trajo consigo muchas críticas que veían cómo a una artista surrealista, libre y creativa, se le limitaba su campo de acción hasta el extremo de encerrarla en un espacio físico reducido, ahogando, con ello, sus ansias creativas y su capacidad para su ruísta deambular urbano. Nadja es, además, el surrealismo en femenino, cuya razón de ser recae en el hecho de liberarse de la angustia de la opresiva y 
absurda lógica del mundo circundante, pero únicamente aquella que se hallaba condicionada por el discurso dominante y no la que se aprehende con la flânerie. Mirka Ahonen (2010: 27) apunta que Breton, al atribuir a Nadja el rol de objeto visual y negarle parcialmente el de sujeto agente, abocándola a cumplir con los estereotipos tradicionales ideados para su sexo, se contradice con la importancia que el movimiento surrealista daba a las iniciativas revolucionarias. Todo lo contrario al proceder de Aragon, quien, recién apartado del movimiento surrealista, en Les cloches de Bâle ${ }^{12}$, escrita en 1934, introducirá a una nueva mujer, libre de las opresiones del patriarcado, que se fundirá también con la ciudad en esa vetada actividad ruista. El poeta y escritor parisino integra el Partido Comunista francés (PCF), en 1927, con el fin de poder comprometerse en la lucha política. Este hecho le hará especial ante el resto de los surrealistas que se negaban a someterse a la voluntad de cualquier grupo social. La relación directa con la ideología política del comunismo-stalinista ${ }^{13}$ va a poderse constatar a lo largo de la obra de Aragon, y muy especialmente a partir de esta novela y de su protagonista femenino, Catherine Simonidzé.

Esta joven muchacha georgiana, hija de un industrial del petróleo que se había quedado en Bakou, Rusia, vive en la ociosidad, sin lograr comprender el movimiento obrero, pero en ella se despertará cierta conciencia política al empezar a leer sobre la revolución socialista y la emancipación femenina. De ahí su determinación de frecuentar a los redactores del periódico L'Anarchie, haciendo suya la consigna de su director, Albert Libertad (1875-1908), cuando declara su postura ante el anarquismo y la libertad misma: "Non, continuait-il, je ne suis pas libre. Mais je veux être libre. La liberté est une fin. Voilà pourquoi je suis anarchiste. Et non pas libertaire. Le courant libertaire de l'anarchisme est un grave danger, il fait prendre l'ombre pour la proie. Nous ne sommes pas nés libres" (Aragon, 1934: 236). En Catherine, se manifestará, por lo tanto, una anarquía moral que la llevará a reclamar la libertad de poder amar sin tapujos y del modo en que ella quisiera. Empero, esa libertad no se manifestará en ella como un imperativo regulativo que obedecer, sino como un fin último en su existencia. Una Ítaca cuyo camino será recorrido con un espíritu anárquico de flâneuse creativa.

Volviendo a la locura de Nadja, aunque alejándonos del surrealismo, esta volverá a constatarse en el amor que Aragon profesaba a su mujer Elsa Triolet, pero también en la válvula de escape que al flâneur ofrece su deambular ruísta. Esa diversificación amatoria puede apreciarse en el poema de Louis Aragon "Elsa je t'aime", recogido dentro de Le Crève-cœur, donde su autor exterioriza el amor que siente por Elsa, el cual se ve condicionado -y exacerbado-por su locura creativa y vivencial:

12 Les cloches de Bâle debe su título al célebre Congreso Internacional Socialista que tuvo lugar en Basilea el 29 y 30 de julio de 1912, con carácter extraordinario, para discutir sobre la política europea y el inminente estado de guerra (Bismuth \& Victor, 2001: 236).

13 Aragon elogiaba la figura de Stalin y todo aquello que representaba, comparando incluso su muerte con la de su propia madre y reafirmando, en repetidas ocasiones, "la confiance française en Staline" (Andermatt, 2005: 98). 


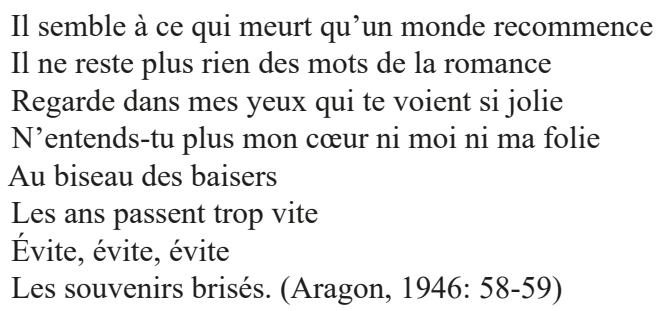

El olvido es, a su vez, cómplice de la locura, una voluntaria desconexión de la realidad que siempre ha traído consigo la destrucción de la memoria para crear un nuevo mundo con otros recuerdos que no tengan más materia originaria que la de los propios sueños. En esta asociación, existe, además, un fuerte vínculo con la fânerie, puesto que el recuerdo implica una constante búsqueda de lo vivido, paseando para ello por los páramos del subconsciente (Nesci, 2007: 314). En Blanche ou l'oubli, Louis Aragon intentará abordar el angustioso interrogante del saber en qué momento se desvanece de la memoria todo aquello que se vive, pues, con ese trágico suceso, desaparece parte de nuestra identidad. La obsesión por el olvido persigue a Aragon, ya que toma la determinación de enfrascarse en la titánica labor de describirlo sin poder dar con las palabras exactas que permitan elucidar claramente el sentido de su presencia. Se intentará, por lo tanto, abordar el fenómeno del olvido, pero también llevar a cabo una cierta reflexión sobre la dinámica de la memoria. Geoffroy Gaiffier, el protagonista de la novela, y alter ego de Aragon, sufre los temibles efectos del olvido, incluso en lo que respecta a su actividad ruista:

Les hommes et les femmes que je vois dans les lieux publics marchent comme des paniers vides. Ils semblent des noix creuses, ou des courants d'air. Pourtant s'il manque à celui-ci un manche, ou le dos de sa chemise à l'autre, ils ont apparence de ne pas s'en apercevoir. On ne leur voit pas inquiétude d'avoir le crâne ouvert ou l'orbite sans œil. Tout se passe comme si l'on avait mis ses idées à la banque, retiré des bijoux aussitôt enfermés dans des coffres à serrures compliquées. Cette humanité ne se défend plus contre l'oubli puisque, ce qu'elle aurait pu oublier, elle en a simplement fait dépôt. (Aragon, 1967: 135)

Al parecer, según lo apuntado en este fragmento, para llevar a cabo convenientemente la flânerie, era preciso evocar el olvido, borrar todo aquello que existía en lo más recóndito del espíritu humano, todo lo que quedaba de recuerdo, de la memoria del tiempo, con el objeto de depositar en un oscuro pozo de misterio contenido todos aquellos sueños que emanaban del subconsciente. 


\section{Conclusión}

Valiéndose de la flânerie, Louis Aragon se apartaba del mundo real circundante para aprehender una nueva panorámica con los rasgos y matices nacidos del subconsciente y del sueño, y así lo manifiesta en su poesía y narrativa. Poco a poco, y a través de su arte, el flâneur permeabiliza su identidad en las aceras por donde circula, ralentizando sus pasos para observar mejor todo aquello que acontece a su alrededor. Este análisis le permite encontrar, en esas imágenes grabadas en el subconsciente, una parcela de inspiración sobre la que depositar su arte. He ahí por lo que, en cierto modo, el flâneur concibe este ruismo como el medio idóneo para concienciar públicamente al imaginario social de su existencia. Una actividad que se lleva a cabo durante las horas diurnas, y con especial ensueño durante las nocturnas, como confesaba hacer Louis Aragon (1963: 116) en su poemario Le Fou d'Elsa, en el que manifiesta que su noctívaga afición era algo de lo que no podía abstenerse.

La flânerie tiende a emplazarse dentro de un contexto determinado del tiempo histórico de la literatura y del arte. Si bien su origen se suele situar en Baudelaire, esta práctica se extendió a lo largo de la pasada centuria, siendo Aragon uno de sus máximos exponentes. De hecho, tanto en uno como en otro escritor, esta actividad creativa no sólo acaeció en el bucólico vagar sobre el asfalto urbano, sino que también se produjo en momentos lóbregos del devenir de la capital francesa: la convulsa revolución de 1848 y la ocupación nazi de 1940 a 1944. En ambas circunstancias críticas, el cielo de París se cubrió de un extenso manto oscuro, no pudiéndose encontrar más luz que la que se filtraba por sus estrechos claros de libertad. Estrellas que se formaban en una dimensión paralela donde el flâneur podía volcar el material tomado de su deambular creativo para dotar de esperanza a sus congéneres errantes. Aragon muestra esta evidencia en Le roman inachevé, cuando constata que había personas que, en vez de pasear, preferían tomar un taxi, no siendo, por lo tanto, demasiado propensas al errar callejero (Aragon, 1956: 159). La modernidad marcaba el tiempo a todos los seres humanos, aunque siempre en función de las características de unos y otros, mostrando, a quienes eran receptivos, el gusto por el paseo en sí y cómo esa paulatina marcha sobre el escenario urbano podría contribuir a transformar la realidad en otra mucho más acorde con su subconsciente y locura vivencial.

Esa fuga de identidad que protagoniza el flâneur, para el poeta y escritor parisino, cristalizaba en París, ciudad por la que él transitaba, transformando, con cada paso que daba, el rostro de esa urbe que deseaba renovar. Sin embargo, el tiempo también metamorfoseaba la ciudad y, con ella, el espacio del que el autor se nutría, pudiéndose dar este fenómeno en cualquier lugar del mundo. Así lo evidencia el propio Aragon en Le roman inachevé, cuando, en los años cincuenta, vuelve a la Unión Soviética tras su primera visita en 1932: 
Je ne reconnais plus les endroits où je passe

Pouchkine a traversé depuis longtemps la place

Et maladroitement comme des mots écrits

Les grilles des jardins sur la candeur d'hiver

Semblent recopier pour les couples ses vers

Le long des boulevards faits pour la flânerie. (Aragon, 1956: 229)

Los versos recién expuestos se encuentran en el poema "La nuit de Moscou", donde la ciudad no sólo se transforma debido al paso del tiempo, sino que los cambios que en ella se producen acontecen dentro de la nocturnidad urbana. En ella, el flâneur, como ocurría con el propio Aragon, apela al amor para modificar el espacio-tiempo con el objeto de convertir las aceras en eminentes senderos por los que llevar a cabo su ruismo. Una actividad que trasladará a su lúdica poética e ingeniosa narrativa para acompasar sus pasos en función de los dictámenes marcados por sus sueños, de los cuales se nutrirá para crear una senda de vida y configurar nuevas geometrías urbanas en su espíritu.

A lo largo de este estudio se ha podido constatar cómo la mirada de Louis Aragon, como avezado flâneur, se proyectaba con cierta frecuencia sobre sus textos. Un creativo modo de observar la realidad que este lo extrapolaba a los personajes de su ficción literaria, buscando, así, extender el campo de acción de su subconsciente más allá de los páramos del olvido, el sueño y el erotismo. Un ejercicio manifiesto en su heterocroma producción literaria, tanto en su etapa surrealista como en aquella influenciada por una marcada tendencia marxista, donde el vagar de las letras permeabilizaba su razón de ser en las calles, aceras y avenidas de aquel París que acogió la flânerie del escritor francés.

\section{Referencias bibliográficas}

Ahonen, Mirka. 2010. "La flânerie féminine dans Nadja d'André Breton" in Havu, Jukka et al. (coord.). Actes du XVIIe Congrès des romanistes scandinaves. Turku, University of Turku, 16-29.

Aliaga, Juan Vicente. 2007. Orden fálico. Androcentrismo y violencia de género en las prácticas artísticas del siglo XX. Tres Cantos (Madrid), Akal.

Andermatt CONLEy, Verena. 2005. Littérature, politique et communisme. Lire "Les lettres françaises”, 1942-1972. Paris, Gallimard.

Aragon, Louis. 1967. Blanche ou l'oubli. Paris, Gallimard.

Aragon, Louis. 1963. Le Fou d'Elsa. Paris, Gallimard.

Aragon, Louis. 1956. Le roman inachevé. Paris, Gallimard.

Aragon, Louis. 1946. Le Crève-cour. Paris, Gallimard. 
Aragon, Louis. 1934. Les cloches de Bâle. Paris, Danoël.

Aragon, Louis. 1926. Le Paysan de Paris. Paris, Gallimard.

ARLt, Roberto. $1995^{1933}$. Aguafuertes porteñas. Madrid, Losada.

BÉNÉzet, Mathieu. 1996. André Breton. Rêveur définitif. Monaco, Éditions du Rocher.

Benjamin, Walter. 1982. "Le Flâneur" dans Charles Baudelaire. Paris, Payot.

Bismuth, Hervé \& Lucien Victor. 2001. Les voyageurs de l'impériale d'Aragon. Neully, Atlande.

BoIreau, Marie-France. 2013. Aragon, romancier de la Grande Guerre et penseur de l'Histoire. Villeneuve d'Ascq, Presses Universitaires du Septentrion.

Bradley, Fiona. 1999. Movimiento en el arte moderno. Serie Tate Gallery. Surrealismo. Madrid, Ediciones Encuentro.

Breton, André. $1998^{1928}$. Nadja. Paris, Gallimard.

Breton, André. 1966 ${ }^{1924}$. Manifeste du surréalisme. Paris, Gallimard.

Broker, Peter. 2013. "General Introduction. Modernity, Modernisms, Magazines" in Brooker, Peter et al. (eds.). The Oxford Critical and Cultural History of Modernist Magazines. Volume III, Europe 1880-1940. Part I. Oxford, Oxford University Press, 1-21.

Caballero Guiral, Juncal. 2002. La mujer en el imaginario surreal. Figuras femeninas en el universo de André Breton. Castelló de la Plana, Publicacions de la Universitat Jaume I.

Chamarat-Malandain, Gabrielle \& Claude Leroy. 2007. Le voyage à Paris. Paris, RITM, Centre des Sciences de la Littérature française de l'Université de Paris X.

Charpentier, Pierre-Frédéric. 2008. La drôle guerre des intellectuels français: 1939-1940. Panazol (Limoge), Lavauzelle.

CUvardic García, Dorde. 2012. El flâneur en las prácticas culturales, el costumbrismo y el modernismo. Paris, Éditions Publibook Université.

DAHLEM, Johannes. 2009. "Transformation du paysage urbain et mélancolie du flâneur dans Berliner Ensemble de Cécile Wajsbrot" in Zimmermann, Margarete (dir.). Après le mur: Belin dans la literature francophone. Tübingen, Narr Verlag, 179-195.

Dupouy, Christine. 2006. La question du lieu en poésie du surréalisme jusqu'à nos jours. Amsterdam/New York, Rodopi B.V.

FOREST, Philippe. 2008. Introduction au Surréalisme: poésie, roman, théâtre. Paris, Vuibert.

Grenouillet, Corinne. 2010. Lecteurs et lectures des Communistes d'Aragon. Paris, Presses Universitaires Franc-Comtoisses.

Havard, Robert. 2004. Companion to Spanish Surrealism. Woodbridge, Tamesis. 
Hoyos Gómez, Camilo. 2013. "Louis Aragon y el quotidien merveilleux surrealista" in Hallazgos. Revista de Investigaciones, $\mathrm{n}^{\circ} 20,75-89$.

Huebner, K. (2014). "Prague Flânerie from Neruda to Nerval” in Wrigley, R. (dir.). The flaneur Abroad. Historical and International Perspectives. Cambridge, Cambridge Scholars Publishing, 281-297.

JAUER, Annick. 2007. L'Allemagne d'Aragon. Aix-en-Provence, Publications de l'Université de Provence.

Kaufmann, Vincent. 2014. Retour sur la ville. Motilité et transformations urbaines. Lausanne, Presses polytechniques et universitaires romandes.

Kopp, Robert. 2008. Album André Breton. Paris, Gallimard.

Lemonnier, Marc. 2008. Chroniques du Paris insolite. Paris, City Éditions.

Martín Otín, José Antonio. 2008. La desesperación del té: (27 veces Pepín Bello). Valencia, Editorial Pre-Textos.

McCABE, Alexandre. 2014. "The Flâneur in the Fog: Phenomenologies of the Northen PortTown Landscape in the Peripatetic Narratives of French Existentialism" in WrIGLEY, R. (dir.). The flaneur Abroad. Historical and International Perspectives. Cambridge, Cambridge Scholars Publishing, 298-306.

Montiel Figueiras, Mauricio. 2005. La errancia: paseos por un fin de siglo. México, D.F., Cal y Arena.

N'Guessan Larroux, Béatrice. 2018 ${ }^{2010}$. Aragon au miroir. Essai sur Le roman inachevé. Paris, L'Harmattan.

NARJoux, Cécile. 2002. Étude sur Aragon. Paris, Ellipses.

Nesci, Catherine. 2007, Le flâneur et les flâneuses. Les femmes et la ville à l'époque romantique. Grenoble, UGA Éditions.

PIÉGay-Gros, Nathalie. 2014. "Mesure et démesure du roman" in Études littéraires, no 45, $35-43$.

SÁnchez Vidal, Agustín. 1996. Buñuel, Lorca, Dalí. El enigma sin fin. Madrid, Planeta.

Scopelliti, Paolo. 2002. L'influence du surréalisme sur la Psychanalyse. Lausanne, L'Âge d'Homme.

SolÀ Solé, Pere. 2014. Louis Aragon y España. Lleida, Edicions i Publicacions de la Universitat de Lleida.

Trudel, Alexandre. 2009. "Des surréalistes aux situationnistes. Sur le passage entre le rêve et l'ivresse" in COnTEXTES, n 6, s.p.

Turcot, K. 2014. "Did the Flâneur Exist? A Parisian Overview" in Wrigley, R. (dir.). The flâneur Abroad. Historical and International Perspectives. Cambridge, Cambridge Scholars Publishing, 40-65. 
Anales de Filología Francesa, n. ${ }^{\circ}$ 29, 2021

JORDI LUENGO LÓPEZ

WALKer, Roselyne. 2005. "Une mythologie dont j'étais à la foi Sphinx et l'CEdipe” in Bougnoux, Daniel (dir.). Aragon, la parole ou l'énigme. Paris, Bibliothèque Centre Pompidou, 28-35.

Walz, Robin. 2000. Pulp Surrealism. Insolent Popular Culture in Early Twentieth-Century Paris. Berkeley/Los Ángeles/London, University of California Press. 
